\title{
Reference Equations for the ADL-Glittre Test in Pediatric Subjects
}

\author{
Renata Martins, Tatiana G Bobbio, Anamaria F Mayer, and Camila IS Schivinski
}

\begin{abstract}
BACKGROUND: The ADL-Glittre test (TGlittre) was initially proposed to evaluate the activities of daily life (ADL) of adults with COPD that involve activities with the upper limbs in addition to walking. Recently, the test has been adapted for children (TGlittre-P), but no reference values have been proposed for its use in this population. The main objective of this study was to develop reference equations for the pediatric adaptation of the TGlittre. METHODS: A cross-sectional study carried out over a period of 19 months. Children 6-14 y old participated in the study. The study was rigorously controlled based on the International Study of Asthma and Allergies in Childhood (ISAAC) questionnaire and on normal spirometry. Study subjects were evaluated for their biometric data (ie, weight, height, body mass index, body surface area, and length of the lower limbs) and spirometric data. Subjects then performed 2 TGlittre-P tests with an interval of 30 min between them. Statistical analysis included a Pearson correlation test to verify a correlation between time spent on the TGlittre-P and biometric variables such as gender and age. Subsequently, a multiple regression analysis was conducted for those variables. The level of signficance was set at a $P$ of 0.05. RESULTS: Eighty-seven children ( 44 girls) participated in the study. Age was the predictive variable with the greatest influence on the time spent on the TGlittre-P (male: adjusted $R^{2}=39.6 \%$; female: adjusted $R^{2}=25.2 \%$ ). The following equations were established: time spent on the TGlittre-P $=3.781-0.083 \times$ age (female), and time spent on the TGlittre$P=4.025-0.123 \times$ age (male). CONCLUSIONS: TGlittre-P reference equations were developed for females and males, with age being the most influential predictive variable in the test performed by children. Key words: child; activities of daily living; functional capacity; evaluation; outcome assessment; reference values. [Respir Care 2019;64(8):937-944. (C) 2019 Daedalus Enterprises]
\end{abstract}

\section{Introduction}

Children with lung diseases often show loss of physical capacity and limitations in their activities of daily life (ADL), ${ }^{1,2}$ most of which are performed with submaximal

\footnotetext{
Ms Martins is affiliated with the Health and Sports Science Center, Physiotherapy Department, Santa Catarina State University, Florianópolis, Brazil. Drs Mayer and Schivinski are affiliated with the Health and Sports Science Center, Physiotherapy Department and Postgraduate Program, Santa Catarina State University, Florianópolis, Brazil. Dr Bobbio is affiliated with Texas A\&M University, College Station, Texas.
}

The authors have disclosed a relationship with the FUMDES/Government of the State of Santa Catarina.

Correspondence: Camila IS Schivinski, Rua Pascoal Simone, 358, Coqueiros, Florianópolis-SC, CEP 88080-350, Brazil. E-mail: cacaiss@yahoo.com.br.

DOI: $10.4187 /$ respcare.06619 efforts. The performance of ADLs reflects functional capacity, ${ }^{3}$ and submaximal tests have been presented as effective evaluation instruments. ${ }^{4}$ For this reason, the 6-min walk test (6MWT) is frequently used because it is easy to apply, inexpensive, and valid and reliable as a measure in children. ${ }^{5-7}$ There are studies that have proposed values and reference equations for predicting the distance covered in the test, ${ }^{8}$ which may further aid in the evaluation of the functional capacity of sick children, as well as in the verification of the effects of the therapeutic intervention in those patients. ${ }^{9,10}$

However, the test does not identify the limitation in upper limb activities, which are often involved in habitual ADLs. ${ }^{11,12}$ In this context, the ADL-Glittre test (TGlittre) was created to more fully evaluate essential ADLs in patients with COPD. ${ }^{11}$ Components of the assessment include activities such as carrying a backpack, sitting and standing up from a chair, going up and down steps, and moving objects with the upper limbs. ${ }^{11}$ The test has been 
shown to induce metabolic, ventilatory, and cardiovascular responses similar to the $6 \mathrm{MWT},{ }^{13}$ and results have been shown to correlate with results of the 6MWT in individuals with COPD $^{11}$ and healthy adults. ${ }^{14}$

To date, most of the studies using the TGlittre have been limited to the population of healthy adults and elderly individuals with COPD and cardiovascular diseases. ${ }^{11,13-17}$ Only 1 study has been conducted in subjects with cystic fibrosis, including children, but the authors used the original protocol of the test. ${ }^{18}$ The TGlittre was adapted for children (TGlittre-P) with adjustments in its components to consider the child's weight and height. ${ }^{19}$ In addition, there is no research on the application of this exclusive pediatric age test, nor are there reference values for its use. The main objective of the study was to develop reference equations for time spent on the TGlittre-P performed by healthy children.

\section{Methods}

This was an observational and cross-sectional analytical study that was carried out over a period of 19 months. The sample consisted of healthy children between the ages of 6 and 14 y old from private and public schools from the Great Florianópolis area in Santa Catarina, Brazil. We included subjects with no history of cardiorespiratory, musculoskeletal, rheumatic, neurological, or hearing and visual deficiencies (data obtained through a health questionnaire written by the researchers) and were not enrolled in high-performance sports federations (ie, non-athletes). We excluded children considered obese by the World Health Organization ${ }^{20}$ and any who were unable to perform or complete any of the evaluation procedures and activities proposed on the day of data collection. Subjects were also excluded if there was evidence of respiratory impairment categorized by the following scores in the asthma module of the International Study of Asthma and Allergies in Childhood (ISAAC) ${ }^{21}$ questionnaire (completed by their parents or legal guardians): $>5$ points for children age $6-9$ y old, and $>6$ points for children 10-14 y old with a change in $\mathrm{FEV}_{1}$ and FVC $<80 \%$ of predicted, and a $\mathrm{FEV}_{1} / \mathrm{FVC}<70 \%$ using the references of Polgar and Promadhat ${ }^{22}$ and Knudson et al. ${ }^{23}$

This study was approved by the Ethics Committee of the State University of Santa Catarina (CAAE: 07635412.3. 0000.0118). Data were collected in the children's schools and at the State University of Santa Catarina. After reading and signing the Informed Consent Letter, parents or guardians of the children also completed a form, developed by the authors, about the general health of the children. Then identification forms with the children's data were completed. Finally, the children were evaluated for their biometric data (ie, weight, height, body mass index, body surface area, ${ }^{24}$ and lower limb length ${ }^{19}$ ) and spirometry

\section{QUICK LOOK}

\section{Current knowledge}

The ADL-Glittre test (TGlittre) includes multi-tasking and essential activities of daily life, and was designed with the purpose of assessing functional capacity more comprehensively. The test has been widely used in populations of adults with chronic diseases and has recently been adapted and validated for children (TGlittre-P).

\section{What this paper contributes to our knowledge}

Reference equations to predict performance by children were developed using the TGlittre-P, one for each gender. Age was identified as the variable with the greatest predictive power for time spent on the TGlittre-P in the developed equations.

results $\left(\mathrm{FEV}_{1}, \mathrm{FVC}\right.$, and $\mathrm{FEV}_{1} / \mathrm{FVC}$ ratio). ${ }^{25}$ After the first phase of evaluations and data analysis, all of the children compatible with the inclusion criteria were referred for the TGlittre-P.

\section{The TGlittre Test Adapted for Children}

The TGlittre-P ${ }^{19}$ has some modifications from the original protocol ${ }^{13}$ in terms of the weight of the backpack to be carried during the test, the height of the shelf, the weight of the objects to be moved on the shelf, and permission for a single verbal stimulus during the test. The TGlittre-P consists of carrying a backpack weighing $0.5-2.5 \mathrm{~kg}$ (ie, the weight depends on the child's gender, age, and weight, according to the World Health Organization ${ }^{26}$ weight and height table) through a circuit with the following sequence of activities: starting from a seated position, the child walks in a flat corridor with a total length of $10 \mathrm{~m}$, with a box at the halfway point $(5 \mathrm{~m})$ with 2 steps to climb and 2 steps to go down (Fig. 1). Each step is $17 \mathrm{~cm}$ high and $27 \mathrm{~cm}$ wide. After going up and down the steps and walking the remaining $5 \mathrm{~m}$ of the course, the child is faced with 2 shelves; the higher shelf (positioned at the height of the child's eyes) has 3 objects that each weigh $0.5 \mathrm{~kg}$, and the child must move the objects one by one to the lower shelf (positioned at the height of the child's waist), and then the child must move them to the floor. The objects are then placed back on the lowest shelf, and then they are moved to the highest shelf. The child then returns along the course until reaching the chair, at which point the child sits in the chair (ie, returns to the initial position). Immediately after (with the stopwatch still activated), the 


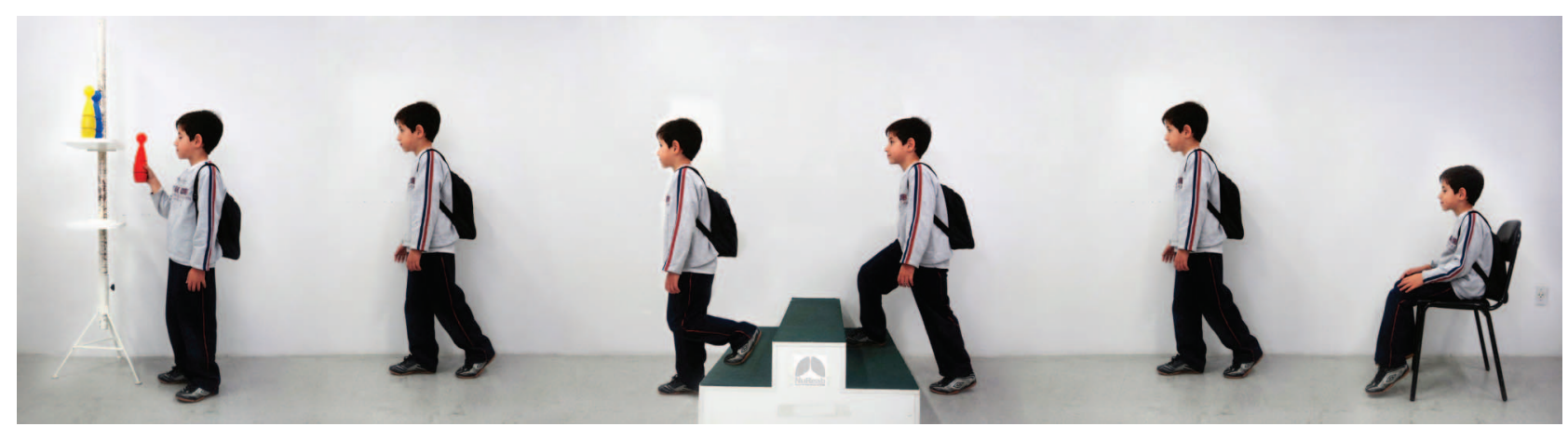

Fig. 1. Representation of the ADL-Glittre test adapted for children (TGlittre-P). From Reference 19, with permission.

child repeats the ADL circuit. The total test includes 5 laps, and the child must complete them in the shortest possible time. Only the verbal stimuli "sit down," and "stand up" are permitted during the test. The test can be suspended when necessary, without stopping the stopwatch. At the end of the test, the completion time is recorded.

As in the original test, children were monitored throughout the course to track heart rate, $\mathrm{S}_{\mathrm{pO}_{2}}$, and dyspnea index (modified Borg scale). ${ }^{27}$ Blood pressure and breathing frequency were checked at the beginning of the test and at the end, with the child in a seated position.

\section{Determination of Reference Values}

For the determination of reference values, the TGlittre-P protocol was performed twice, with a 30-min interval between tests. The children remained at rest during the interval period, which was enough time for the cardiorespiratory parameters to return to baseline. The tests were explained and conducted by the same evaluator, as were the collection of control parameters during the test (heart rate, $\mathrm{S}_{\mathrm{pO}_{2}}$, and dyspnea index). A second researcher monitored breathing frequency and blood pressure to ensure that the parameters were checked immediately after the test was completed. The best test result was used for analysis.

\section{Sample Size Calculation}

For the calculation of the sample size, 2 objectives were considered: we needed to determine the mean $(95 \% \mathrm{CI})$ of the TGlittre-P time parameter of each age group, specific for males and females, and we needed to determine the most appropriate model of the parameter considering age and height. To match the first objective, we analyzed the pilot study data $(n=10)$, from which the sample size was calculated for each gender. ${ }^{28}$ For this study, the SD of $9.6 \mathrm{~s}$ and a delta $(\Delta)$ of $3 \mathrm{~s}$ were considered to determine the 95\% CI of the mean. ${ }^{29}$ These data showed that 40 students of each sex were estimated to be sufficient to obtain a good estimate of the average time spent on the TGlittre-P for children. To match the second objective, regression analysis, we considered a gender-specific model because sexual dimorphism plays an important role in cardiorespiratory assessments. For that model, 2 predictive variables were determined: age and height. Thus, when requiring at least 20 children for each predictive variable the sample totaled 40 boys and 40 girls. ${ }^{28}$ Contemplating objectives 1 and 2, we estimated the sample size to be 40 children for each gender, for a total of 80 students.

\section{Statistical Analysis}

The data were transcribed to a spreadsheet with statistical analysis performed with SPSS software (version 20.0, IBM, Armonk, New York). Data were presented through descriptive statistics and frequencies, expressed as mean, $\mathrm{SD}$, minimum, maximum, and median. The Shapiro-Wilk and Kolmogorov-Smirnov tests were used to evaluate the normality of the variables, and the Pearson correlation test (following the Dancey and Reidy classification ${ }^{30}$ ) was used to verify the correlation between the time spent on the TGlittre-P (dependent variable) and the variables of weight, height, age, and body mass index. Subsequently, simple linear regression models were developed for each predictive variable that showed a correlation with the dependent variable. Afterward, the predictive equations, specific to each gender, were developed with stepwise multiple linear regression. The probability for the inclusion of a predictive variable in the model was $P \leq .05$. To choose the best model, the adjusted coefficient of determination (adjusted $\mathrm{R}^{2}$ ) and the theoretical reference adopted by the authors were considered. The mean time of this study was inserted into the best-generated model and compared to the reference values of the equation through the independent $t$ test. 


\section{Reference Equations for the Pediatric ADL-Glittre Test}

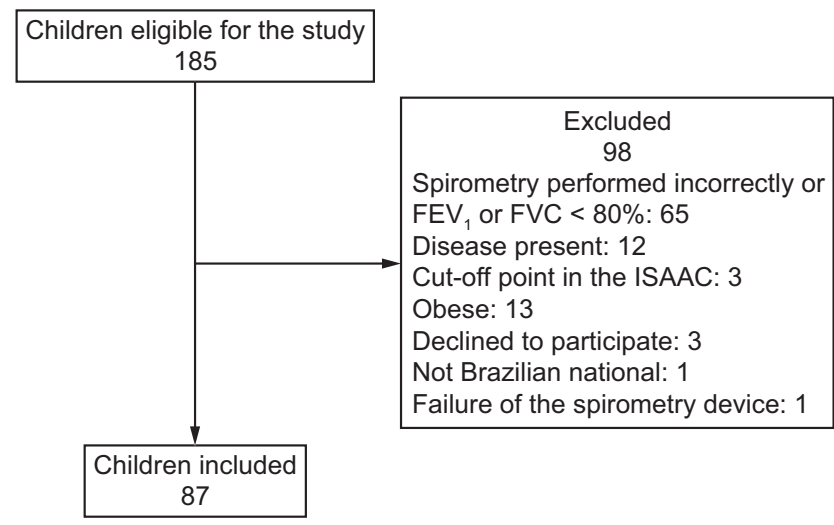

Fig. 2. Flow chart. ISAAC = International Study of Asthma and Allergies in Childhood.

\section{Results}

A total of 185 children were eligible for the study (Fig. 2). Of these, 98 were excluded, leaving 87 subjects in the study (44 female and 43 male); 58 subjects were white ( 26 female), 15 were black ( 10 female), and 14 were brownskinned (8 female). Descriptive data characterizing age, biometric data, spirometric parameters, final scores of the asthma module of the ISAAC questionnaire, and time spent on both TGlittre-P tests are described in Table 1, as is the comparison of the variables between the genders ( $P$ value on the independent $t$ test).

The relationship between the main variables and the time spent on the TGlittre-P is shown in Table 2, based on the Pearson correlation coefficient values. Age was the variable that correlated most closely with the time spent on the test, with a moderate negative correlation. ${ }^{30}$ Subsequently, height and length of the lower limbs (right lower limb in boys and left lower limb in girls) also showed moderate negative correlations in both genders. ${ }^{30}$

The models of the developed equations, considering the variables of age, weight, height, and length of lower limbs, are described in Table 3. The highest coefficients of determination $\left(R^{2}\right.$ and adjusted $\left.R^{2}\right)$ are related to the variable age. In that regard, the model was chosen to generate the estimated values of time spent on the TGlittre-P, and the comparison between the average time of the studied sample and the reference values from the equation was carried out (Table 3). The average time spent on the test, according to each age of the studied sample, was equal to or similar to the time proposed by the developed reference equation (considering the age variable). There was no statistical difference between the time estimated by the equation and the time verified in the sample $(P=0.550$ (female), $P=1.000$ (male)). Table 4 presents the subjects' performance on the TGlittre-P by age, as well as the value estimated by the equation that included the variable age.

\section{Discussion}

One of the main objectives of this study was to develop reference equations for the TGlittre-P test, recently published to evaluate the functional capacity of children. ${ }^{20}$ Children with respiratory diseases suffer from a reduction in their functional capacity, which consequently interferes with their quality of life. 1,2,31,32 Knowing that the individual response to exercise provides information related to the respiratory, cardiac, metabolic, and muscular systems, ${ }^{33,34}$ this type of assessment is extremely important because it analyzes the individual's capacity to perform activities. Subsequently, the most commonly used test in children is the 6MWT, although it is not exclusively adapted for children. Studies show that results may be influenced by anthropometric factors, such as gender and age, and by previously established reference values and equations. ${ }^{7,8}$

The TGlittre test, which is useful in evaluating functional capacity in patients with COPD, ${ }^{11}, 14$ has been discussed in studies that investigate the applicability of the test. ${ }^{11,13-18} \mathrm{How}$ ever, no TGlittre tests have been performed exclusively with children, including the version adapted for children, the TGlittre-P. ${ }^{19}$ Despite the growing recognition of TGlittre-P, equations and reference values for this version of the test have not been developed yet. To our knowledge, ours is the first study to attempt such a proposal. Use of the TGlittre-P will enable evaluation of functional capacity in both healthy and sick children through a test that involves multiple tasks, and not just walking as with the 6MWT.

The proposal for adapting the test for pediatric application considered the fact that a child is in constant growth as well as physical and intellectual development. ${ }^{35}$ The test incorporates aspects that are age-appropriate. The adapted test proved to be feasible, and the children performed it effectively. ${ }^{19}$ The mean performance was $2.84 \pm 0.41 \mathrm{~min}$ (equivalent to approximately $2 \min 50 \mathrm{~s}$ ), which was comparable to the time elapsed in the test performed by healthy adults $(2.84 \pm 0.45 \mathrm{~min}) .{ }^{17}$ However, subjects with COPD, the largest group currently benefitting from this evaluation, ${ }^{13}$ spent an average time of $4.77 \pm 1.46 \mathrm{~min}$ (approximately $4 \mathrm{~min} 46 \mathrm{~s}$ ). Consequently, a cutoff point of $3 \mathrm{~min} 30 \mathrm{~s}$ has been identified for adult patients with COPD who undergo TGlittre. The TGlittre has features designed for older patients with impaired functional capacity. ${ }^{16}$

Variables such as sex, height, age, race, and weight can greatly influence the results of lung function tests ${ }^{36}$ and physical capacity assessment. ${ }^{37}$ The results of our study corroborate this information, showing a significant difference between male and female children in the variables of body mass index $(P=.039)$ and percent of predicted $\operatorname{FEV}_{1}(P=.02)$. Furthermore, this study set out to establish different reference equations for females and males. According to the literature, there is an influence of weight and height, but the greatest 
Table 1. Characterization of the Sample and Comparison Between Genders

\begin{tabular}{|c|c|c|c|c|c|c|c|}
\hline \multirow{2}{*}{ Subject Characteristics } & \multicolumn{2}{|c|}{ Mean \pm SD } & \multicolumn{2}{|c|}{ Minimum-Maximum } & \multicolumn{2}{|c|}{ Median } & \multirow{2}{*}{$P$} \\
\hline & Female & Male & Female & Male & Female & Male & \\
\hline Age, y & $10.48 \pm 2.30$ & $10.23 \pm 2.35$ & $6-14$ & $6-14$ & 10.50 & 10.00 & .63 \\
\hline \multicolumn{8}{|l|}{ Biometric parameters } \\
\hline Weight, kg & $40.45 \pm 11.72$ & $36.47 \pm 10.87$ & $18.3-63.7$ & $21.3-61.5$ & 42.90 & 34.90 & .11 \\
\hline Height, cm & $144.79 \pm 13.27$ & $142.19 \pm 14.39$ & 117.0-172.0 & $119.0-169.40$ & 145.25 & 143.00 & .38 \\
\hline Body mass index, $\mathrm{kg} / \mathrm{m}^{2}$ & $18.86 \pm 3.15$ & $17.70 \pm 2.24$ & $13.11-26.07$ & $13.96-23.00$ & 18.97 & 17.37 & .039 \\
\hline Body surface area, $\mathrm{m}^{2}$ & $1.27 \pm 0.23$ & $1.21 \pm 0.23$ & $0.77-1.71$ & $0.85-1.66$ & 1.30 & 1.21 & .17 \\
\hline RLL length, cm & $78.72 \pm 8.51$ & $76.71 \pm 8.97$ & $58.00-91.93$ & $57.73-91.70$ & 80.50 & 76.66 & .29 \\
\hline LLL length, $\mathrm{cm}$ & $78.79 \pm 8.52$ & $76.83 \pm 8.94$ & $57.60-91.80$ & $57.53-91.70$ & 80.40 & 76.33 & .30 \\
\hline \multicolumn{8}{|l|}{ Spirometry parameters } \\
\hline $\mathrm{FEV}_{1}, \%$ & $90.27 \pm 8.32$ & $94.58 \pm 8.79$ & $80-117$ & $80-113$ & 88.00 & 93.00 & .02 \\
\hline $\mathrm{FVC}, \%$ & $97.73 \pm 10.77$ & $99.65 \pm 8.20$ & $83-129$ & $85-120$ & 94.50 & 99.00 & .35 \\
\hline $\mathrm{FEV}_{1} / \mathrm{FVC}, \%$ & $86.48 \pm 5.47$ & $86.58 \pm 7.30$ & $73-99$ & $76-124$ & 87.00 & 87.00 & .94 \\
\hline $\mathrm{FEF}_{25-75 \%}, \%$ & $89.39 \pm 21.90$ & $89.93 \pm 19.64$ & $46-139$ & $53-150$ & 88.50 & 87.00 & .90 \\
\hline Peak expiratory flow, $\%$ & $82.07 \pm 14.19$ & $82.70 \pm 13.50$ & $58-119$ & $52-112$ & 82.00 & 83.00 & .83 \\
\hline ISAAC score (asthma) & $1.14 \pm 1.63$ & $0.93 \pm 1.40$ & $0-5$ & $0-6$ & 0 & 0 & .53 \\
\hline \multicolumn{8}{|l|}{ TGlittre Time, min } \\
\hline Trial 1 & $3.03 \pm 0.43$ & $2.97 \pm 0.57$ & $2.33-4.31$ & $2.13-4.43$ & 3.00 & 2.85 & .62 \\
\hline Trial 2 & $2.91 \pm 0.36$ & $2.76 \pm 0.45$ & $2.30-3.98$ & $2.08-3.61$ & 2.93 & 2.70 & .11 \\
\hline \multicolumn{8}{|c|}{$\begin{array}{l}\text { Independent } t \text { test. } n=44 \text { female subjects; } n=43 \text { male subjects. } \\
\text { RLL }=\text { right lower limb } \\
\text { LLL = left lower limb } \\
\text { FEF }_{25-75 \%}=\text { forced expiratory flow during the middle half of the FVC maneuver } \\
\text { ISAAC = International Study of Asthma and Allergies in Childhood }\end{array}$} \\
\hline
\end{tabular}

Table 2. Correlation Between Time Spent on the TGlittre-P and Key Variables

\begin{tabular}{lccccr}
\hline \hline \multirow{2}{*}{$\begin{array}{c}\text { Correlation } \\
\text { Between TGlittre-P } \\
\text { Time and: }\end{array}$} & \multicolumn{2}{c}{$\begin{array}{c}\text { Correlation } \\
\text { of Coefficient }\end{array}$} & & \multicolumn{2}{c}{$P$} \\
\cline { 2 - 3 } \cline { 5 - 6 } & Female & Male & & Female & Male \\
\hline Age & -0.519 & -0.641 & & $<.001$ & $<.001$ \\
Weight & -0.365 & -0.455 & & .02 & .002 \\
Height & -0.430 & -0.533 & & .004 & $<.001$ \\
Body mass index & -0.238 & -0.281 & & .12 & .068 \\
RLL length & -0.403 & -0.512 & & .007 & $<.001$ \\
LLL length & -0.406 & -0.506 & & .006 & .001
\end{tabular}

Pearson correlation test. Pearson correlation classification: $r=0.10-0.30$, weak; $r=0.40-0.6$, moderate; $r=0.70-1.0$, strong.

$n=44$ female subjects; $n=43$ male subjects.

$\mathrm{LLL}=$ left lower limb

RLL $=$ right lower limb

influence is that of age (adjusted $\mathrm{R}^{2}=25.2 \%$ and $39.6 \%$ for girls and boys, respectively) over the time elapsed in the test. Our findings corroborate the study that developed reference equations for the TGlittre in adults, in which the variables age, height, and body mass index were also relevant for predicting performance in the test. ${ }^{17}$

A systematic review of reference values for the 6MWT in children and adolescents published in 2016 identified a total of 32 prediction equations for reference values. The variable age was included in most (64\%) equations, followed by height $(61 \%),{ }^{8}$ because chronological age and biological maturation lead to increased height and body mass in children. The latter is, in general, a reflection of a larger amount of muscle mass. ${ }^{38}$ Moreover, the increased growth and development is responsible for a significant gain in muscle strength, speed, flexibility, endurance, agility, and cardiorespiratory fitness, ${ }^{38,39}$ which may reflect in a shorter test execution time for older children. In addition, biomechanical factors are directly related to those increases because the larger the body size, the longer the leg length, which generates a more efficient lever in the execution of the movements. ${ }^{39}$

The finding that age was the greatest influence on test results, similar to the $6 \mathrm{MWT}$, reinforces what Malina et $\mathrm{al}^{40}$ found in their study. According to the authors, subjects who were advanced in sexual and skeletal maturity within a chronological age group performed better on tasks of strength, power, and speed compared to those who were less mature. Therefore, the TGlittre-P test result is influenced by the development process, considering that older children perform the test in a shorter time. A limitation of this study is the fact that we did not control for sexual maturation. Future studies should evaluate the influence of this variable on the performance of the 
Table 3. Reference Equations for the TGlittre-P and Comparison of Reference Values and Times Observed in the TGlittre-P Test

\begin{tabular}{|c|c|c|c|c|}
\hline & TGlittre-P Reference Equation & $\mathrm{R}^{2}$ & Adjusted $\mathrm{R}^{2}$ & $P$ \\
\hline \multicolumn{5}{|l|}{ Female } \\
\hline \multicolumn{5}{|l|}{ Simple linear regression } \\
\hline Age & $3.781-(0.083 \times$ Age $)$ & .270 & .252 & $<.001$ \\
\hline Height & $4.639-(0.012 \times$ Height $)$ & .185 & .165 & .004 \\
\hline Weight & $3.376-(0.011 \times$ Weight $)$ & .133 & .113 & .02 \\
\hline \multicolumn{5}{|l|}{ Multiple linear regression } \\
\hline Age, height, and weight (stepwise) & $3.781-(0.083 \times \text { Age })^{*}$ & .270 & .252 & $<.001$ \\
\hline Enter & $\begin{array}{c}3.675-(0.118 \times \text { Age })+(0.001 \times \\
\text { Height })+(0.006 \times \text { Weight })\end{array}$ & .286 & .232 & .003 \\
\hline Weight and RLL length (stepwise) & $4.285-(0.017 \times \mathrm{RLL}) \dagger$ & .160 & .143 & .007 \\
\hline \multicolumn{5}{|l|}{ Male } \\
\hline \multicolumn{5}{|l|}{ Simple linear regression } \\
\hline Age & $4.025-(0.123 \times$ Age $)$ & .410 & .396 & $<.001$ \\
\hline Height & $5.151-(0.017 \times$ Height $)$ & .284 & .267 & $<.001$ \\
\hline Weight & $3.457-(0.019 \times$ Weight $)$ & .207 & .187 & .002 \\
\hline \multicolumn{5}{|l|}{ Multiple linear regression } \\
\hline Age, height, and weight (stepwise) & $4.025-(0.123 \times \text { Age })^{*}$ & .410 & .396 & $<.001$ \\
\hline Enter & $\begin{array}{c}3.661-(0.181 \times \text { Age })+(0.005 \times \\
\text { Height })+(0.008 \times \text { Weight })\end{array}$ & .435 & .392 & $<.001$ \\
\hline Weight and RLL length (stepwise) & $4.741-(0.026 \times \mathrm{RLL}) \dagger$ & .262 & .244 & $<.001$ \\
\hline 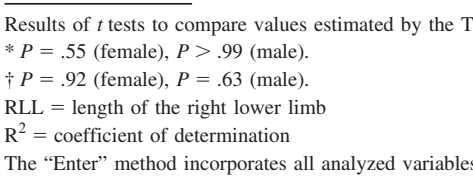 & tions and the times observed in the study. & & & \\
\hline
\end{tabular}

Table 4. Mean TGlittre-P Time Observed Compared to the Equation Estimate

\begin{tabular}{|c|c|c|c|c|}
\hline \multirow[t]{2}{*}{ Age, y } & \multicolumn{2}{|c|}{$\begin{array}{l}\text { Time of TGlittre-P } \\
\text { Estimated by the } \\
\text { Age Equation, min }\end{array}$} & \multicolumn{2}{|c|}{$\begin{array}{c}\text { Mean Time } \\
\text { of TGlittre-P } \\
\text { Presented by } \\
\text { the Sample, min }\end{array}$} \\
\hline & Female* & Male $\dagger$ & Female & Male \\
\hline 6 & 3.28 & 3.28 & 3.34 & 3.35 \\
\hline 7 & 3.20 & 3.16 & 3.28 & 3.29 \\
\hline 8 & 3.11 & 3.04 & 3.16 & 2.92 \\
\hline 9 & 3.03 & 2.91 & 3.09 & 2.91 \\
\hline 10 & 2.95 & 2.79 & 2.72 & 2.66 \\
\hline 11 & 2.86 & 2.67 & 3.03 & 2.72 \\
\hline 12 & 2.78 & 2.54 & 2.65 & 2.46 \\
\hline 13 & 2.70 & 2.42 & 2.73 & 2.49 \\
\hline 14 & 2.61 & 2.30 & 2.76 & 2.31 \\
\hline \multicolumn{5}{|c|}{$\begin{array}{l}n=44 \text { female subjects; } n=43 \text { male subjects. } \\
\text { * EQUATION: time spent on the TGlittre } P=3.781-0.083 \times \text { Age. } \\
\dagger \text { EQUATION: time spent on the TGlittre- } P=4.025-0.123 \times \text { Age. }\end{array}$} \\
\hline
\end{tabular}

test because it can be a determinant in the children's performance.

Another important aspect of in pediatrics is the measurement of the lower limbs; although we included this variable, it is not considered in functional tests. Children grow and have growth spurts, and thus larger stature may be related to longer lower limbs. ${ }^{38}$ These changes can result in greater stride and, consequently, higher velocity in the test. We found that lower limb length had a moderate negative correlation (female: -0.403 in the right lower limb and -0.406 in the left lower limb; male: -0.512 in the right lower limb and -0.506 in the left lower limb) with the time spent on the TGlittre-P, which counters the work of Malina et al. ${ }^{40}$

The influence of other measures and variables, in addition to lower limb measurement, should also be considered in the performance of tests like the TGlittre-P in children, such as muscular strength, wingspan, balance, coordination, and ability. The TGlittre-P is composed of several types of activities that integrate psychomotor elements, such as the need to be agile and coordinated to move objects quickly, balance during sitting and rising from the chair and going up and down steps, and muscle strength to be able to perform the whole test as quickly as possible. The analysis of those abilities and capacities is relevant because children manifest their acquisition or improvement at different times. Although these aspects were not evaluated directly in this study, they are evaluated indirectly with the execution of the TGlittre-P. 


\section{Reference Equations for the Pediatric ADL-Glittre Test}

In addition to the inherent complexity of the test, there are other elements pertinent to the pediatric age group, whose growth process is influenced by genetic (intrinsic), environmental, nutritional, social, economic, and cultural (extrinsic) factors. ${ }^{41}$ Tests like this evaluate not only physical abilities, but they also indirectly evaluate motivational factors of the subject, willingness to perform requested activities, and the ability to understand instructions.

Another limitation of our study was that accelerometry evaluation was not introduced to verify the subjects' level of physical activity. However, special care was taken to exclude children who participate regularly in athletic activities. In addition, criteria related to global health should be considered for rating children as healthy.

From a functional point of view, the results of the TGlittre-P test performed by children was compatible with the time spent by a healthy adult, which provides a logical basis for clinical indication. In addition, the reference equations developed here may help the early assessment of functional capacity in children with respiratory diseases, as well as provide a means to follow up and verify the effect of treatment on those patients. To this end, studies evaluating the predictive validity of these equations in chronic childhood diseases, such as bronchiolitis obliterans, cystic fibrosis, asthma, and bronchiectasis, should now be conducted with the TGlittre-P. This test can also be used to identify general changes in functional capacity, both in children with respiratory diseases and in children with other conditions.

\section{Conclusion}

Reference equations to predict performance by children were developed on the TGlittre-P, one for each gender. Age is the most influential predictive variable in time spent on the TGlittre-P, an ideal test for assessing the functional capacity of children.

\section{REFERENCES}

1. Andrade LB, Silva DA, Salgado TL, Figueroa JN, Lucena-Silva N, Britto MC. Comparison of six-minute walk test in children with moderate/severe asthma with reference values for healthy children. J Pediatr 2014;90(3):250-257.

2. Aznar S, Gallardo C, Fiuza-Luces C, Santana-Sosa E, López-Mojares LM, Santalla A, et al. Levels of moderate-vigorous physical activity are low in Spanish children with cystic fibrosis: a comparison with healthy controls. J Cyst Fibros 2014;13(3):335-340.

3 . Chen JJ. Functional capacity evaluation and disability. Iowa Orthop J 2007;27:121-127.

4. Kocks JW, Asijee GM, Tsiligianni IG, Kerstjens HA, Van Der Molen T. Functional status measurement in COPD: a review of available methods and their feasibility in primary care. Prim Care Respir J 2011;20(3):269-275.

5. Li AM, Yin J, Yu CC, Tsang T, So HK, Wong E, et al. The sixminute walk test in healthy children: reliability and validity. Eur Respir J 2005;25(6):1057-1060.
6. Geiger R, Strasak A, Treml B, Gasser K, Kleinsasser A, Fischer V, et al. Six-minute walk test in children and adolescents. J Pediatr 2007;150(4):395-399.

7. Martins R, Gonçalves RM, Mayer AF, Schivinski CI. Reliability and reproducibility of six-minute walk test in healthy children. Fisioter Pesq 2014;21(3):279-284.

8. Mylius CF, Paap D, Takken T. Reference value for the 6-minute walk test in children and adolescents: a systematic review. Expert Rev Respir Med 2016;10(12):1335-1352.

9. Priesnitz CV, Rodrigues GH, Stumpf CS, Viapiana G, Cabral CP, Stein RT, et al. Reference values for the 6-min walk test in healthy children aged 6-12 years. Pediatr Pulmonol 2009;44(12):1174-1179.

10. D'silva C, Vaishali K, Venkatesan P. Six-minute walk test-normal values of school children aged 7-12 y in India: a cross-sectional study. Indian J Pediatr 2012;79(5):597-601.

11. Skumlien S, Hagelund T, Bjørtuft $\varnothing$, Ryg MS. A field test of functional status as performance of activities of daily living in COPD patients. Respir Med 2006;100(2):316-323.

12. Carpes MF, Mayer AF, Simon KM, Jardim JR, Garrod R. The Brazilian Portuguese version of the London Chest Activity of Daily Living scale for use in patients with chronic obstructive pulmonary disease. J Bras Pneumol 2008;34(3):143-151.

13. Karloh M, Karsten M, Pissaia FV, Araújo CLP, Mayer AF. Physiological responses to the Glittre-ADL Test in patients with chronic obstructive pulmonary disease. J Rehabil Med 2014;46(1):88-94.

14. Corrêa KS, Karloh M, Martins LQ, Santos K, Mayer AF. Can the Glittre ADL test differentiate the functional capacity of COPD patients from that of healthy subjects? Braz J Phys Ther 2011;15(6): 467-473.

15. Fernandes-Andrade AA, Britto RR, Soares DCM, Velloso M, Pereira DAG. Evaluation of the Glittre-ADL test as an instrument for classifying functional capacity of individuals with cardiovascular diseases. Braz J Phys Ther 2017;21(5):321-328.

16. Gulart AA, Munari AB, Klein SR, da Silveira LS, Mayer AF. The Glittre-ADL Test Cut-Off Point to Discriminate Abnormal Functional Capacity in Patients with COPD. COPD 2018;15(1):73-78.

17. Reis CM, Karloh M, Fonseca FR, Biscaro RRM, Mazo GZ, Mayer AF. Functional capacity measurement: reference equations for the Glittre Activities of Daily Living test. J Bras Pneumol 2018;44(5): 370-377.

18. Arikan H, Yatar I, Calik-Kutukcu E, Aribas Z, Saglam M, VardarYagli N, et al. A comparison of respiratory and peripheral muscle strength, functional exercise capacity, activities of daily living and physical fitness in patients with cystic fibrosis and healthy subjects. Res Dev Disabil 2015;45-46:147-156.

19. Martins R, de Assumpção MS, Bobbio TG, Mayer AF, Schivinski C. The validity and reliability of the ADL-Glittre test for children. Physiother Theory Pract 2018. doi: 10.1080/09593985.2018.1457747.

20. De Onis M, Onyango AW, Borghi E, Siyam A, Nishida C, Siekmann J. Development of a WHO growth reference for school-aged children and adolescents. Bull World Health Organ 2007;85(9):660-667.

21. Behl RK, Kashyap S, Sarkar M. Prevalence of bronchial asthma in school children of 6-13 years of age in Shimla city. Indian J Chest Dis Allied Sci 2010;52(3):145-148.

22. Polgar G, Promadhat V. Standard values. In: Pulmonary Function Testing in Children: Techniques and Standards, 1st edition. Philadelphia: WB Saunders;1971:87-122.

23. Knudson RJ, Slatin RC, Lebowitz MD, Burrows B. The maximal expiratory flow-volume curves: normal standards variability and effect of age. Am Rev Respir Dis 1976;113(5):587-600.

24. Du Bois D, Du Bois EF. Clinical calorimetry: tenth paper a formula to estimate the approximate surface area if height and weight be known. Arch Intern Med 1916;17(6):863-871. 


\section{Reference Equations for the Pediatric ADL-Glittre Test}

25. Miller MR, Hankinson J, Brusasco V, Burgos F, Casaburi R, Coates A, et al. Standardisation of spirometry. Eur Respir J 2005;26(2):319-338.

26. World Health Organization: Physical status: the use and interpretation of anthropometry. WHO Technical Report Series 854: Geneva; 1995:161-255.

27. ATS Committee on Proficiency Standards for Clinical Pulmonary Function Laboratories. ATS statement: guidelines for the six-minute walk test. Am J Respir Crit Care Med 2002;166(1):111-117.

28. Freund JE, Simon GA. Applied Statistics: Economy, Administration and Accounting, 9th edition. Porto Alegre, Brazil: Bookman;2000: 202-536.

29. Hair JF Jr, Anderson RE, Tathan RL, Black WC. Multivariate Data Analysis, 5th edition. Upper Saddle River, New Jersey: Prentice Hall;1998:148-668.

30. Dancey C, Reidy J. Statistics Without Mathematics to Psychology: Using SPSS for Windows, 3rd edition. Porto Alegre, Brazil: Artmed; 2006: 525-608.

31. Silva CM, Barros L, Simões F. Health-related quality of life in paediatric asthma: children's and parents' perspectives. Psychol Health Med 2015;20(8):940-954.

32. Vandeleur M, Walter LM, Armstrong DS, Robinson P, Nixon GM, Horne RSC. Quality of life and mood in children with cystic fibrosis: associations with sleep quality. J Cyst Fibros 2018;17(6):811-820.

33. Nixon PA. Role of exercise in the evaluation and management of pulmonary disease in children and youth. Med Sci Sports Exerc 1996;28(4):414-420.
34. Palange P, Ward SA, Carlsen KH, Casaburi R, Gallagher CG, Gosselink R, et al. Recommendations on the use of exercise testing in clinical practice. Eur Respir J 2007;29(1):185-209.

35. Malina R, Bouchard C, Bar-Or O. Growth, Maturation and Physical Activity, 2nd edition. Champaign, IL: Human Kinetics;2004:41-231.

36. Culver BH, Graham BL, Coates AL, Wanger J, Berry CE, Clarke $\mathrm{PK}$, et al. Recommendations for a standardized pulmonary function report. An official American Thoracic Society technical statement. Am J Respir Crit Care Med 2017;196(11):1463-1472.

37. Okuro RT, Schivinski CIS. Teste de caminhada de seis minutos em pediatria: relação entre desempenho e parâmetros antropométricos. Fisioter Mov 2013;26(1):219-228.

38. Ré AHN, Bojikian LP, Teixeira CP, Böhme MTS. Relações entre crescimento, desempenho motor, maturação biológica e idade cronológica em jovens do sexo masculino. Rev Bras Educ Fís Esp 2005;19(2):153-162.

39. Ulbrich AZ, Bozza R, Machado HS, Michelin A, Vasconcelos IQA, Neto AS, et al. Aptidão física em crianças e adolescentes de diferentes estágios maturacionais. Fit Perf J 2007;6(5):277-282.

40. Malina RM, Eisenmann JC, Cumming SP, Ribeiro B, Aroso J. Maturity-associated variation in the growth and functional capacities of youth football (soccer) players 13-15 years. Eur J Appl Physiol 2004;91(5-6):555-562.

41. Romani SAM, Lira PIC. Fatores determinantes do crescimento infantil. Rev Bras Saúde Matern Infant 2004;4(1):15-23. 